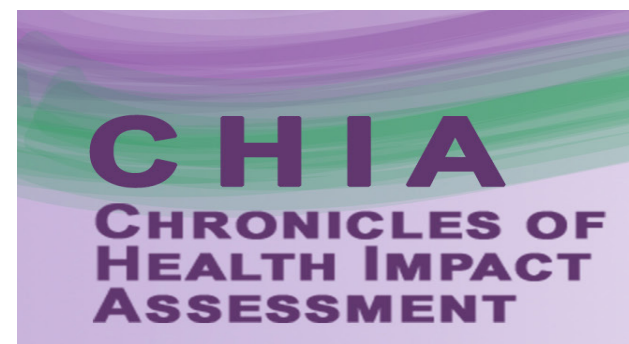

Improving community health through health impact assessments

October 2016

Volume 1, ISSUE 1

\title{
A BRIEF HISTORY OF HEALTH IMPACT ASSESSMENTT IN THE UNITED STATES
}

\author{
Andrew L. Dannenberg, MD, MPH
}

\section{Background}

In recent decades, several factors have contributed to the increasing use of health impact assessment (HIA) in the United States. Initially in California and subsequently in other states, communities that have been traditionally disenfranchised began seeing HIA as an opportunity to address the issues impacting their lives and to increase their ability to participate in decision-making processes about those issues. Second, public health professionals began to better understand the links between health and the natural and built environments, and to use HIA as a tool to improve cross-disciplinary communication. Third, public health professionals recognized that HIA could be valuable to address economic and social issues, such as educational and wage policies, in addition to built environment issues, such as land use and transportation. Some of the major milestones in the growth of the use of HIA in the United States are listed in Figure 1.

The National Environmental Policy Act in 1969 (NEPA, 1969) required evaluation of the environmental effects of any "major federal action significantly affecting the quality of the human environment." In recognizing of the interdependence of environmental quality and human health, NEPA was designed "to promote efforts which will prevent or eliminate damage to the environment and biosphere and stimulate the health and welfare of man" (NEPA, 1969 \4321) and to "assure for all Americans safe, healthful, productive and aesthetically and culturally pleasing surroundings" (NEPA ,1969 \$4331; Bhatia, 2008).

While NEPA could be used to examine health impacts of projects and policies routinely, in practice, health has received relatively little attention in most environmental impact assessments (EIAs). For example, EIAs commonly estimate the change in air quality (an environmental impact) resulting from a proposed project or policy, but do not estimate the associated change in respiratory disease rates (a health impact) that could be expected from that change in air quality. The inclusion of health in the EIA process has been encouraged by the National Research Council report on HIA (NRC, 2011) and discussed in several reviews (Cole, 2004; Bhatia, 2008). Examples in which health issues have been incorporated into the EIA process include the Lake Oswego to Portland Transit Project HIA in Oregon (http:// www.pewtrusts.org/hip/portland-to-lake-oswego-transitproject.html) and the HIA of oil and gas leasing in the National Petroleum Reserve in Alaska's North Slope Borough (Wernham, 2007).

In 1986, the World Health Organization's (WHO) Ottawa Charter for Health Promotion was a major step toward the development of HIA. The charter recognized that achieving health requires working across multiple sectors to fulfill basic human needs including: peace, shelter, education, food, income, a stable eco-system, sustainable resources, social justice, and equity (http://www.who.int/healthpromotion/ conferences/previous/ottawa/en/). In 1997, the WHO Jakarta Declaration on Leading Health Promotion into the $21^{\text {st }}$ Century specifically called for the use of "equity-focused health impact assessments as an integral part of policy development" (http://www.who.int/healthpromotion/conferences/ previous/jakarta/declaration/en/index2.html). Substantial work on HIA in the 1990s, primarily in Europe, led to the publication of the WHO Gothenburg Consensus Paper that delineated the core principles of HIA practice including democracy, equity, sustainable development, and ethical use of evidence (WHO, 1999).

\section{RICHARD M. FAIRBANKS SCHOOL OF PUBLIC HEALTH}

INDIANA UNIVERSITY IUPUI

\section{THE SOCIETY OF PRACTITIONERS OF HEALTH IMPACT ASSESSMENT SOPHIA}


Figure 1. Selected milestones in the development of health impact assessment in the US. Adapted from Ross 2014 and HarrisRoxas 2012

\begin{tabular}{|l|l|}
\hline 1969 & $\begin{array}{l}\text { National Environmental Policy Act passes that included among its purposes to "promote efforts ... [to] stimu- } \\
\text { late the health and welfare of man" }\end{array}$ \\
\hline 1986 & $\begin{array}{l}\text { World Health Organization's Ottawa Charter for Health Promotion recognizes that achieving health requires } \\
\text { working across multiple sectors }\end{array}$ \\
\hline 1997 & $\begin{array}{l}\text { WHO Jakarta Declaration calls for the use of "equity-focused health impact assessments as an integral part of } \\
\text { policy development" }\end{array}$ \\
\hline 1999 & WHO releases the Gothenburg consensus paper on HIA \\
\hline 2001 & $\begin{array}{l}\text { San Francisco Department of Public Health publishes a paper on the health benefits of a living wage ordi- } \\
\text { nance, the first HIA in the US (Bhatia 2001) }\end{array}$ \\
\hline 2004 & First book on HIA published, primarily with European contributors (Kemm 2004) \\
\hline 2006 & CDC documents steps to advance HIA in the US, based on 2004 CDC/RWJF workshop (Dannenberg 2006) \\
\hline 2006 & University of California Berkeley teaches first graduate school course on HIA in the US \\
\hline 2008 & CDC documents first 27 HIAs conducted in the US (Dannenberg 2008) \\
\hline 2008 & North American HIA Practice Standards Working Group releases version 1 of practice standards for HIAs \\
\hline 2008 & Washington state requires an HIA for State Route 520 bridge replacement, the first HIA required in the US \\
\hline 2008 & First HIA of the Americas workshop held in Oakland, CA \\
\hline 2009 & Massachusetts Healthy Transportation Compact requires HIAs for transportation projects \\
\hline 2011 & $\begin{array}{l}\text { National Research Council publishes Improving Health in the United States: The Role of Health Impact Assessment to } \\
\text { guide future of HIA in the US (NRC 2011) }\end{array}$ \\
\hline 2011 & Society of Practitioners of Health Impact Assessment (SOPHIA) established \\
\hline 2012 & First National HIA conference held in Washington, DC, sponsored by RWJF \\
\hline 2014 & First textbook on HIA in the US published (Ross 2014) \\
\hline 2014 & First sector-specific review of HIAs in the US published (Dannenberg 2014) \\
\hline 2015 & Evaluation of the impact of HIAs in the US published (Bourcier 2015) \\
\hline 2016 & Over 380 HIAs completed or in progress in the US \\
\hline 2016 & First issue of Chronicles of Health Impact Assessment published \\
\hline
\end{tabular}

\section{Early HIA work in the US}

Early work on HIA in the US was led by the San Francisco Department of Public Health, the UCLA School of Public Health, and Partnership for Prevention (http://www. prevent.org; Cole, 2008). In 1999, the first HIA conducted in the US described the health impacts of a living wage ordinance in San Francisco; however, it was not called an HIA at that time (Bhatia, 2001). In 2004, Cole discussed the potential for expanded use of HIA in the US and identified a number of reports on health impacts of various issues outside of the health sector, such as gambling and building codes. However, many of these reports did not focus prospectively on a specific policy or project and should not be considered HIAs (Cole, 2004). The fact that one can assess the health impacts of any topic (such as air pollution or sea level rise), yet not be doing a health impact assessment, leads to confusion of terminology that persists now. Most HIAs are conducted prospectively on a proposed policy or project in which decision-makers are willing to consider recommendations to promote health or mitigate adverse health impacts. HIAs that are not timely or in which decision-makers have little receptiveness to recommendations are of less value, although they may still facilitate community engagement.

Community engagement has long been a central component of HIA work (Wright, 2005; Tamburrini, 2011; CCHE, 2015). Much of the early work in the San Francisco Bay area focused on efforts with local community partners to address health equity issues. Initial work to shape HIA practice to be relevant to communities included sessions in which public health and community partners worked to identify the scope of hypothetical HIAs. After trust between public health professionals and community constituencies was established, these local partners began to call on public health to use HIA to help with their project and policy struggles. In one early success, an HIA by the San Francisco Department of Public Health contributed to the building of affordable replacement housing for low income 
residents in Trinity Plaza Apartments who were being displaced by the development of market rate condominiums (Bhatia, 2007). The creation of the non-profit organization Human Impact Partners (http://www.humanimpact.org/) in 2006 in Oakland added to the field's capacity to conduct HIAs. Similar progress in the mid-2000's was made in Alas$\mathrm{ka}$, where work on the health impacts of resource extraction on native Alaskan communities led to substantial expansion in the use of HIA by the Alaska state health department (Wernham, 2007; Anderson, 2013).

In 2002, the Centers for Disease Control and Prevention (CDC) hosted a multi-disciplinary workshop in Atlanta to develop a research agenda to advance the field of the relation between health and the built environment (Dannenberg, 2003). The resulting research agenda listed health impact assessment as one of the recommended approaches worthy of further research. As a result, in 2004, the Robert Wood Johnson Foundation (RWJF) and CDC hosted a second multi-disciplinary workshop, including HIA experts from Europe and Canada, to explore approaches to further develop the use of HIA in the US (Dannenberg, 2006). This workshop suggested next steps including conducting pilot HIAs, creating a database of completed HIAs, building capacity to train HIA practitioners, evaluating the impacts of HIAs, and identifying more resources to expand the field. The results of this workshop, as well as the early HIA successes in California and Alaska, contributed to the expanded involvement of both RWJF and CDC in HIA activities in subsequent years. As described below, progress has been made in each of the workshop's recommended next steps.

\section{Academic research}

In addition to the conduct of numerous HIAs, the field of HIA has grown in the United States and internationally over the past 15 years as an area of academic research. Two books (NRC, 2011; Ross, 2014) and approximately 85 peerreviewed articles (Figure 2) with U.S. authors have been published since 2001. Some articles focused on HIA methods, such as challenges in conducting HIAs (Krieger, 2003), use of quantitative methods in HIA (Bhatia, 2011), use of stakeholder consultation in HIAs (Tamburrini, 2011), and modeling of traffic noise exposures (Seto, 2007). Other articles have focused on the effectiveness of HIAs (Bourcier, 2015), teaching HIA courses in universities (Pollack 2015), and a review of HIA guidelines (Hebert, 2012). Papers focused on the use of HIA in specific sectors include: transportation (Dannenberg, 2014), housing (Morley, in preparation), and education (Gase, in preparation). A few articles focused on the conduct and results of a single HIA, such as local speed limits in Massachusetts (James, 2014), zoning revisions in Baltimore (Johnson Thornton, 2013), and the Atlanta Beltline transit and redevelopment project (Ross, 2012). Now containing over 380 HIAs, the HIA database created by the Health Impact Project has been a valuable resource for identifying relevant HIAs for research and practice (The Pew Charitable Trusts, 2016).
Figure 2. Number of articles with US authors related to

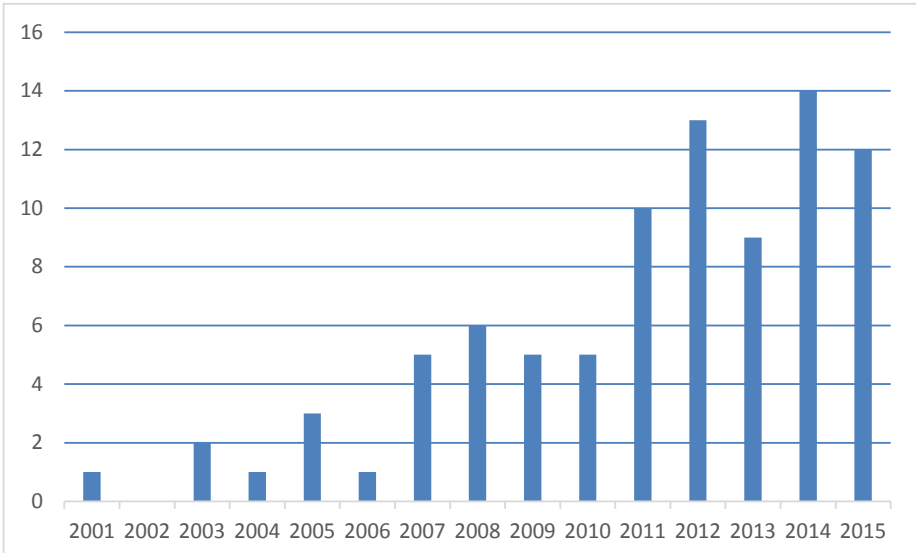

Source: http://www.cdc.gov/healthyplaces/docs/hiaarticles usauthors 29february2016.pdf

Teaching and training

As the demand for conducting HIAs has grown over the past decade, there has been a parallel increase in the demand for training professionals to conduct HIAs. For several years, HIA workshops were organized by the CDC, the National Association of County and City Health Officials, and the American Planning Association with local public health and planning officials in the same classroom to increase their cross-disciplinary collaboration. From 2006 to 2012, over 2200 people in 29 states were trained in at least 75 in-person short courses on HIA by four organizations: CDC, the San Francisco Department of Public Health, the non-profit Human Impact Partners, and the University of California, Berkeley (Schuchter, 2015). Based on interviews of a sample of trainees, Schuchter reported that many trainees had met their training objectives, established new collaborations at the trainings, and disseminated what they learned.

In about 2008, the American Planning Association and the National Association of County and City Health Officials developed a free six-hour on-line training course on HIA that has since attracted several thousand users (http:// advance.captus.com/planning/hia2/home.aspx). At least five universities teach graduate level courses focused on HIA; a number of students in these courses have subsequently taken jobs that involve the use of HIA skills (Pollack, 2015). National capacity to conduct HIAs has been strengthened by the founding of the Society of Practitioners of Health Impact Assessment (SOPHIA) (http://hiasociety.

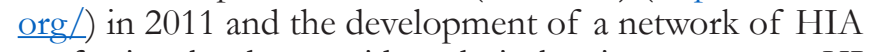
professionals who provide technical assistance to new HIA practitioners with support from the Health Impact Project and others.

\section{National and international conferences}

The growth of HIA conferences over the past decade has helped advance the field by facilitating interactions among HIA practitioners. Six national HIA workshops have been held in Oakland, California, beginning in 2008 (http:// hiasociety.org/?page id=833). These workshops include 75- 
100 experienced HIA practitioners and focus on advancing HIA practices. Three national HIA conferences have been held in Washington, DC, beginning in 2012 (http://www. pewtrusts.org/en/projects/health-impact-project/researchand-analysis/presentations-and-webinars). These conferences each attracted 400-500 participants ranging from novices to experienced HIA practitioners, and have been primarily sponsored by the Robert Wood Johnson Foundation. In addition, HIA practitioners from the US have participated in some of the thirteen international HIA conferences during 1998-2013, held primarily in Europe except for the 2012 conference in Quebec (http://www.apho.org.uk/resource/ browse.aspx?RID =93284).

HIA guidelines and standards Early work on developing guidelines and standards for HIA was associated with creating structured reports for HIA projects conducted by the HIA class taught at UC Berkeley that began in 2006. This work was furthered by activities associated with the HIA workshops in Oakland and led to the most recent version entitled Minimum elements and practice standards for health impact assessment (Bhatia, 2014). While this document recommends standards for HIA conduct, the actual practice of HIA in the US varies widely on issues such as engaging stakeholders, formulating actionable recommendations, and providing an implementation plan for follow-up.

\section{Evaluation}

The need to evaluate the impact of HIAs on subsequent decisions and health outcomes was evident from early in the growth of the field (Dannenberg, 2006). Several process evaluations have examined whether specific HIAs followed recommended methods (Schuchter, 2014; US EPA, 2013). The largest impact evaluation conducted in the US included detail case studies of 23 HIAs and concluded that "HIAs are a useful tool to promote public health because they can influence decisions in non-health-related sectors, strengthen cross-sector collaborations, and raise awareness of health issues among decision makers" (Bourcier, 2015). Findings from this study were similar to those from HIA evaluations conducted in Europe (Davenport, 2006; Wismar, 2007) and in Australia (Haigh, 2013). Several studies have specifically documented facilitators and barriers to successful HIAs (Davenport, 2006; Bourcier, 2015: Haigh, 2015; Dannenberg, 2016).

\section{Funding}

No consistent source of funding has been routinely available to conduct HIAs in the US. Many HIAs have been conducted with support from the Health Impact Project (a collaboration of RWJF and The Pew Charitable Trusts, http://www.pewtrusts.org/en/projects/health-impactproject) [see related HLA article from Health Impact Project in this issue of $C H I A]$. A number of HIAs have been supported by The California Endowment, Blue Cross and Blue Shield of
Minnesota Foundation, Kansas Health Institute, RWJF's Active Living Research program, and other foundations. Other HIAs have been funded by the CDC's Healthy Community Design Initiative, either directly or through partners such as the National Association of County and City Health Officials and the National Network of Public Health Institutes. Some HIAs have been conducted by health departments within the scope of their existing resources or by students enrolled in graduate school HIA courses (Pollack, 2015).

\section{Institutionalization}

The National Research Council report on HIA stated "HIA is a particularly promising approach for integrating health implications into decision-making" (National Research Council, 2011). In recent years, there has been increasing interest in multisectoral approaches to health promotion, often called Health in All Policies (HiAP). An executive order by the governor of California in 2010 set up a task force to advance the use of HiAP in the state (http://sgc.ca.gov/s hiap.php). HIA is a tool that can be used to further the HiAP approach (Collins, 2009; Gase, 2013).

The National Prevention Council (which includes 17 primarily non-health agencies) in its National Prevention Strategy states that "opportunities for prevention increase when those working in housing, transportation, education, and other sectors incorporate health and wellness into their decision making" (p. 2) and that HIA "can be used to help decision makers evaluate project or policy choices to increase positive health outcomes and minimize adverse health outcomes and health inequities" (National Prevention Council, 2011, p. 15). Other national reports that encourage the use of HIA include the White House Task Force on Childhood Obesity (White House Task Force, 2010), the Department of Health and Human Services Healthy People 2020 report (US DHHS, 2012), and the CDC's transportation and health policy statement (CDC, 2011).

State legislators have proposed or adopted a number of bills that include certain elements of an HIA. The National Conference of State Legislatures (Farquhar, 2014) reported that 55 bills in 17 states supportive of HIA or its components were introduced during 2009-2014, but few passed into law. Among successful HIA-related bills, a bill in Washington state mandated an HIA as part of funding for the State Route 520 bridge replacement in Seattle (Seattle King County Public Health, 2008), and the Massachusetts Healthy Transportation Compact mandated HIAs in transportation-related projects (Massachusetts Department of Transportation, 2009). In Alaska, the use of HIA has been institutionalized with funding support from the state's natural resources permitting process (http://dhss.alaska. gov/dph/Epi/hia/Pages/default.aspx; Anderson, 2013). In Washington state, "health impact reviews" are conducted on proposed legislation by the State Board of Health when requested by the governor or a state legislator (http://sboh. wa.gov/OurWork/HealthImpactReviews). 


\section{Conclusion}

The use of HIA has grown substantially over the past 15 years since it was first introduced in the US. Familiarity with HIA has greatly increased both among public health professionals and decision-makers in other sectors and among many community groups. HIA is proving valuable as a tool to facilitate community engagement and empowerment, even in cases where changes in a decision explicitly due to that HIA may be difficult to document. HIAs have been useful in sectors well beyond the built environment, including topics such as incarceration, gambling, living wages, after school programs, and climate change policies.
Little is known about the impact of policies that encourage or require the use of HIAs; further research on this topic would be valuable. Challenges to the further expansion of HIA use include the need for reliable funding sources and the potential for pushback in an anti-regulatory environment. In the long term, as the awareness of health impacts increases in other sectors, it may be possible to achieve healthy outcomes without needing to conduct a formal HIA on every proposed individual project and policy. Should it occur, such an accomplishment would be due in large part to the success of the hundreds of HIAs that have been and are being done now. 


\section{References}

Anderson, P. J., Yoder, S., Fogels, E., Krieger, G., \& McLaughlin, J. (2013). The State of Alaska's early experience with institutionalization of health impact assessment. International Journal of Circumpolar Health, 72. http://dx.doi.org/10.3402/ ijch.v72i0.22101

Bhatia, R. (2007). Protecting health using an environmental impact assessment: a case study of San Francisco land use decision making. American Journal of Public Health. 97(3):406-413. http://dx.doi.org/10.2105/AJPH.2005.073817

Bhatia, R., Farhang, L., Heller, J., Lee, M., Orenstein, M., Richardson, M., \& Wernham, A. (2014). Minimum elements and practice standards for health impact assessment, Version 3. September. http://hiasociety.org/wp-content/uploads/2013/11/HIA-Practice-Standards-September-2014.pdf

Bhatia, R., \& Wernham, A. (2008). Integrating human health into environmental impact assessment: An unrealized opportunity for environmental health and justice. Environmental Health Perspectives, 116(8):991-1000. http://dx.doi.org/10.1289/ ehp.11132

Bhatia, R., Seto, E. (2011). Quantitative estimation in Health Impact Assessment: Opportunities and challenges. Environmental Impact Assessment Review, 31:301-309. http://dx.doi.org/10.1016/i.eiar.2010.08.003

Bhatia, R., Katz, M. (2001). Estimation of health benefits from a local living wage ordinance. American Journal of Public Health, 91(9):1398-1402. http://dx.doi.org/10.2105/AJPH.91.9.1398

Bourcier, E., Charbonneau, D., Cahill, C., \& Dannenberg, A. L. (2015). An evaluation of health impact assessments in the United States, 2011-2014. Preventing Chronic Disease, 12:140376. http://dx.doi.org/10.5888/pcd12.140376

Center for Community Health and Evaluation (CCHE) and Human Impact Partners. (2015). Community Participation in Health Impact Assessments: A National Evaluation. Seattle, WA. December. http://www.humanimpact.org/wp-content/ uploads/Full-report Community-Participation-in-HIA-Evaluation.pdf

Centers for Disease Control and Prevention. (2011) CDC Recommendations for Improving Health through Transportation Policy. http://www.cdc.gov/transportation/

Cole, B. L., Wilhelm, M., Long, P. V., Fielding, J. E., Kominski, G., \& Morgenstern, H. (2004). Prospects for health impact assessment in the United States: new and improved environmental impact assessment or something different? Journal of Health Politics, Policy and Law, 29(6):1153-1186. http://dx.doi.org/10.1215/03616878-29-6-1153

Cole, B. L., \& Fielding, J. (2008). Building Health Impact Assessment (HIA) Capacity: A Strategy for Congress and Government Agencies. Partnership for Prevention. https://www.prevent.org/data/files/initiatives/buildignhealthimpactassessmenthiacapacity.pdf

Collins, J., \& Koplan, J. P. (2009). Health impact assessment: a step toward health in all policies. Journal of the American Medical Association, 302(3): 315-317. http://dx.doi.org/10.1001/jama.2009.1050

Dannenberg, A. L. (2016). Effectiveness of health impact assessment: a synthesis of five impact evaluation studies. Submitted to Preventing Chronic Disease (revise and resubmit). http://dx.doi.org/10.5888/pcd13.150559

Dannenberg, A. L., Bhatia, R., Cole, B. L., Dora, C., Fielding, J. E., Kraft, K.,...Tilson, H. H. (2006). Growing the field of health impact assessment in the United States: an agenda for research and practice. American Journal of Public Health, 96(2):262-270. http://dx.doi.org/10.2105/AJPH.2005.069880

Dannenberg, A. L., Jackson, R. J., Frumkin, H., Schieber, R. A., Pratt, M., Kochtitzky, C., \& Tilson, H. H. (2003). The impact of community design and land-use choices on public health: a scientific research agenda. American Journal of Public Health, 93:1500-1508. http://dx.doi.org/10.2105/AJPH.93.9.1500

Dannenberg, A. L., Bhatia, R., Cole, B. L., Heaton, S. K., Feldman, J. D., Rutt, C. D. (2008). Use of health impact assessment in the U.S.: 27 case studies, 1999-2007. American Journal of Preventive Medicine, 34(3):241-256. http://dx.doi.org/10.1016/j. amepre.2007.11.015

Dannenberg, A. L., Ricklin, A., Ross, C. L., Schwartz, M., West, J., White, S., \& Wier, M. L. (2014) Use of health impact assessment for transportation planning: importance of transportation agency involvement in the process. Transportation Research Record: Journal of the Transportation Research Board, 2452:71-80. http://dx.doi.org/10.3141/2452-09

Davenport, C., Mathers, J., \& Parry, J. (2006). Use of health impact assessment in incorporating health considerations in decision making. Journal of Epidemiology and Community Health, 60(3):196-201. http://dx.doi.org/10.1136/jech.2005.040105

Farquhar, D. (2014). National Conference of State Legislatures. An analysis of state health impact assessment legislation. http://www.ncsl.org/research/environment-and-natural-resources/an-analysis-of-state-health-impact-assessment-legislation635411896.aspx

Gas, L. N., DeFosset, A., Gakh, M., Harris, E. C., Weisman, S. R., \& Dannenberg, A. L. (Submited). Review of educationfocused health impact assessments conducted in the United States, 2003-2015. Journal of School Health.

Gase, L. N., Pennotti, R., \& Smith, K. D. (2013). "Health in All Policies": Taking stock of emerging practices to incorporate health in decision making in the United States. Journal of Public Health Management and Practice, 19(6):529-540. http:// dx.doi.org/10.1097/phh.0b013e3182980c6e 
Haigh, F., Baum, F., Dannenberg, A. L., Harris, M. F., Harris-Roxas, B., Keleher, H.,...Harris, E. (2013). The effectiveness of health impact assessment in influencing decision-making in Australia and New Zealand 2005-2009. BMC Public Health, 13:1188. http://dx.doi.org/10.1186/1471-2458-13-1188

Haigh, F., Harris, E., Harris-Roxas, B., Baum, F., Dannenberg, A. L., Harris, M. F.,...Spickett, J. (2015). What makes health impact assessments successful? Factors contributing to effectiveness in Australia and New Zealand. BMC Public Health, 15:1009. http://dx.doi.org/10.1186/s12889-015-2319-8

Harris-Roxas, B., Viliani, F., Bond, A., Cave, B., Divall, M., Furu, P.,...Winkler, M. (2012). Health impact assessment: the state of the art. Impact Assessment and Project Appraisal, 30(1): 43-52. http://dx.doi.org/10.1080/14615517.2012.666035

Hebert, K. A., Wendel, A. M., Kennedy, S. K., \& Dannenberg, A. L. (2012). Health impact assessment: a comparison of 45 local, national, and international guidelines. Environmental Impact Assessment Review, 34:74-82. http://dx.doi. $\underline{\operatorname{org} / 10.1016 / j . e i a r .2012 .01 .003}$

James, P., Ito, K., Banay, R. F., Buonocore, J. J., Wood, B., \& Arcaya, M. C. (2014). A health impact assessment of a proposed bill to decrease speed limits on local roads in Massachusetts. International Journal of Environmental Research and Public Health, 11(10):10269-10291. http://dx.doi.org/10.3390/ijerph111010269

Johnson Thornton, R. L., Greiner, A., Fichtenberg, C. M., Feingold, B. J., Ellen, J. M., \& Jennings, J. M. (2013). Achieving a healthy zoning policy in Baltimore: results of a health impact assessment of the TransForm Baltimore zoning code rewrite. Public Health Reports, 128(suppl 3):87-103. http://www.publichealthreports.org/issueopen.cfm?articleID=3056

Kemm, J., Parry, J., \& Palmer, S. (2004). Health impact assessment: concepts, theory, techniques, and applications. Oxford: Oxford University Press. http://dx.doi.org/10.1093/acprof:oso/9780198526292.001.0001

Krieger, N., Northridge, M., Gruskin, S., Quinn, M., Kriebel, D., Davey Smith, G.,...Miller, C. (2003). HIA “promise and pitfalls" conference group. Assessing health impact assessment: multidisciplinary and international perspectives. Journal of Epidemiology and Community Health, 57(9):659-662. http://www.ncbi.nlm.nih.gov/pmc/articles/PMC1732566/pdf/ v057p00659.pdf

Massachusetts Department of Transportation. (2009). Healthy Transportation Compact. National Center for Health Housing. (2016). A Systematic Review of Health Impact Assessments on Housing Decisions and Guidance for Future Practice. March. http://www.nchh.org/Portals/0/Contents/Guidance-for-Conducting-HIAs-on-Housing-Decisions.pdf

National Environmental Policy Act of 1969 (NEPA). (1969). Public Law 91-190, 42 U.S.C. 4321-4347. https://www.epa.gov/ laws-regulations/summary-national-environmental-policy-act

National Prevention Council, National Prevention Strategy. (2011). Washington, DC: US Department of Health and Human Services, Office of the Surgeon General.

National Research Council of the National Academies. (2011). Improving health in the United States: the role of health impact assessment. Washington, DC: National Academies Press. http://www.nap.edu/catalog.php?record id=13229

Pollack, K. M., Dannenberg, A. L., Botchwey, N. D., Stone, C. L., \& Seto, E. (2015). Developing a model curriculum for a university course in health impact assessment in the USA. Impact Assessment and Project Appraisal, 33(1):80-85. http:// dx.doi.org/10.1080/14615517.2014.960213

Ross, C. L., Leone de Nie, K., Dannenberg, A. L., Beck, L. F., Marcus, M. J., \& Barringer, J. (2012). Health Impact Assessment of the Atlanta BeltLine. American Journal of Preventive Medicine, 42(3):203-213. http://dx.doi.org/10.1016/j. amepre.2011.10.019

Ross, C. L., Orenstein, M., \& Botchwey, N. (2014). Health Impact Assessment in the United States. New York: Springer. http://dx.doi.org/10.1007/978-1-4614-7303-9

Schuchter, J., Bhatia, R., Corburn, J., \& Seto, E. (2014). Health impact assessment in the United States: Has practice followed standards? Environmental Impact Assessment Review, 47:47-53. http://dx.doi.org/10.1016/j.eiar.2014.03.001

Schuchter, J., Rutt, C., Satariano, W. A., \& Seto, E. (2015). Building capacity for health impact assessment: training outcomes from the United States. Environmental Impact Assessment Review, 50:190-195. http://dx.doi.org/10.1016/j. eiar.2014.10.002

Seattle and King County Public Health. (2008). SR520 Health Impact Assessment: A bridge to a healthier community. http:// www.kingcounty.gov/healthservices/health/ehs/hia.aspx

Seto, E. Y., Holt, A., Rivard, T., \& Bhatia, R. (2007). Spatial distribution of traffic induced noise exposures in a US city: an analytic tool for assessing the health impacts of urban planning decisions. International Journal of Health Geographics, 6:24. http://dx.doi.org/10.1186/1476-072X-6-24

Tamburrini, A., Gilhuly, K., \& Harris-Roxas, B. (2011). Enhancing benefits in health impact assessment through stakeholder consultation. Impact Assessment and Project Appraisal, 29(3):195-204. http://dx.doi.org/10.3152/14615511 $\underline{1 X 12959673796281}$

The Pew Charitable Trusts. (2016). Health Impact Project. Health impact assessments in the United States database. http:// www.pewtrusts.org/en/multimedia/data-visualizations/2015/hia-map 
U.S. Department of Human Services. (2008). Healthy People 2020. http://www.healthypeople.gov/2020/about/advisory/ $\underline{\text { Reports }}$

U.S. Environmental Protection Agency. (2013). A Review of Health Impact Assessments in the U.S.: Current State-of-Science, Best Practices, and Areas for Improvement. https://cfpub.epa.gov/si/si_public record_report.cfm?direntryid $=266763$

Wernham, A. (2007). Inupiat health and proposed Alaskan oil development: Results of the first Integrated Health Impact Assessment/Environmental Impact Statement of proposed oil development on Alaska's North Slope. EcoHealth, 4(4):500513. http://dx.doi.org/10.1007/s10393-007-0143-z

White House Task Force on Childhood Obesity. (2010). Report to the President. Solving the problem of childhood obesity within a generation. May. http://www.letsmove.gov/white-house-task-force-childhood-obesity-report-president

Wismar, M., Blau, J., Ernst, K., \& Figueras, J. (2007). The effectiveness of health impact assessment: scope and limitations of supporting decision-making in Europe. European Observatory on Health Systems and Policies. Brussels. http://www.euro. who.int/ data/assets/pdf file/0003/98283/E90794.pdf

World Health Organization Regional Office for Europe. (1999). Health impact assessment: main concepts and suggested approach. Gothenburg Consensus Paper. Brussels. http://www.apho.org.uk/resource/item.aspx?RID=44163

Wright, J., Parry, J., \& Mathers, J. (2005). Participation in health impact assessment: objectives, methods and core values. Bulletin of the World Health Organization, 83:58-63. http://www.scielosp.org/pdf/bwho/v83n1/v83n1a14.pdf

\section{CORRESPONDING AUTHOR}

Andrew L. Dannenberg, MD, MPH

Affiliate Professor

School of Public Health and College of Built Environments

University of Washington, Seattle

adannen@uw.edu

\section{ACKNOWLEDGEMENTS}

We thank Rajiv Bhatia and Jonathan Heller for their helpful comments on a draft of this paper.

\section{CHIA STAFF}

Editor-in-Chief

Cynthia Stone, Richard M. Fairbanks School of Public Health Indiana University-Purdue University Indianapolis

Journal Manager

Lyndy Kouns, Richard M. Fairbanks School of Public Health Indiana University-Purdue University Indianapolis

Chronicles of Health Impact Assessment Vol. 1, No. 1 (2016) DOI: 10.18060/21348

(c) 2016 Author(s): Dannenberg, A.L.

(cc)BY

This work is licensed under a Creative Commons Attribution 4.0 International License. 